\title{
Game Design Combined with Science Workshop for Increasing Motivation in Studying Science in Children
}

\author{
Sara Hojjat ${ }^{1}$, Chiaki Fukuzaki ${ }^{1}$, Tomoyuki Sowa ${ }^{2}$ \\ ${ }^{1}$ Graduate School of Kobe Design University, Kobe City, Japan \\ ${ }^{2}$ Kobe Design University, Kobe City, Japan \\ Email: sara_hojjat@yahoo.com,fukuzakichiaki@gmail.com,tomoyukisowa@gmail.com
}

Received 1 March 2016; accepted 28 May 2016; published 31 May 2016

Copyright (C) 2016 by authors and Scientific Research Publishing Inc.

This work is licensed under the Creative Commons Attribution International License (CC BY). http://creativecommons.org/licenses/by/4.0/

(c) (i) Open Access

\begin{abstract}
Many studies have been conducted to discover ways to increase the motivation of students in science classes. The research project discussed here, examines attempt to increase the motivation of elementary school students in basic science by the means of designing a science game. To realize this goal, the maze and mirror game was designed and a workshop was held based on the game in the Shimada elementary school which teaches the concepts of light and reflection during joyful group play. The game was initially designed for this research consisted of a maze pattern, mirrors and bases, a buzzer and a laser. The results were evaluated by three types of questionnaires and showed improvement in all aspects. The questionnaires revealed that they could develop their knowledge of light and reflection, $91 \%$ of students liked the game very much and $81 \%$ favored having these kinds of games in their science classes. The main achievement of this game in motivating students in studying science can be categorized into four main areas: Creating thinking and independent learning, playful learning atmosphere, a chance to learn in group activities, and a feeling of accomplishment.
\end{abstract}

\section{Keywords}

Game Design, Maze and Mirror Game, Interactive Design, Science Workshop, Playful Learning

\section{Introduction}

Many efforts have been made to introduce science teaching methods that can motivate students to learn science. The Physics Education Technology Project Team of the Department of Physics of the University of Colorado at

How to cite this paper: Hojjat, S., Fukuzaki, C., \& Sowa, T. (2016). Game Design Combined with Science Workshop for Increasing Motivation in Studying Science in Children. Art and Design Review, 4, 41-55.

http://dx.doi.org/10.4236/adr.2016.42007 
Boulder performed research on "High-Tech Tools for Teaching Physics” (Finkelstein, Adams, Keller, Perkins, \& Wieman, 2006). They introduced a new suite of computer simulations and demonstrated that "simulations are more productive for developing student conceptual understanding than reading resources, or chalk-talk lectures.” [ibid] Another attempt of this group was directed towards promoting children's understanding and interest in science through informal science education. They presented results from the University of Colorado's Partnership for Informal Science Education in the Community (PISEC) in which university participants work in afterschool programs on inquiry-based activities with primary school children from populations typically underrepresented in science. This university-community partnership is designed to positively impact youth, university students, and the institutions that support them to improve children's attitudes towards a better understanding of science. Children worked through hands-on activities adapted from the Physics and Everyday Thinking (PET) curriculum and demonstrated better understanding of content area as well as favorable beliefs about science (Bartley, Mayhew, \& Finkelstein, 2009). Priscilla Laws et al., presented "Chautauqua” short courses on "Promoting Active Learning in Introductory Physics Courses” at The University of Sydney, and Swinburne University of Technology (Laws, College, Sokoloff, \& Thornton, 1999). This article outlines the rationale for these courses, and presents brief examples of activities from active learning physics curricula developed by the activity-based physics group. Initial results show that activity-based, computer-supported, interactive learning environments well serve the diversity of students studying physics. Some attempt was also directed toward a discipline-based method to develop physics instruction by Redish (1994).

Love for and/or interest in science begins in elementary schools (Spencer \& Walker, 2015). Younger children tend to be more curious and motivated to learn. The pipeline for increasing the number of people interested in science fields begins in these formative years. Inquiry-based strategies incorporate questioning and active engagement for student learning. Efforts on designing games and combining them with science workshops will provide a chance for children to enjoy these games broadly, while their motivation and enthusiasm for learning science may increase and help them to face the challenges or learning sciences such as physics in high school and later.

In this research, by designing a game and a science workshop based on that including reflection by RTV, we prepare a situation for students to enter a game, and enjoy, learn and share their experiences while they're learning about light, mirror and reflection. One of the steps of this workshop is preparing Real Time Video (RTV) which is taken simultaneously during the workshop. During the workshop, two camera men take photos and videos, and at the same time make a 4-minute video of the workshop. At the end of the workshop, this clip is shown to participants who reflect the students, their group and the other groups' activities. In this workshop, the RTV allowed children to understand their strong and weak points and consider them in the possible next steps, giving them a good chance to improve their learning of science achieved in the game and for the researchers to study their reaction to the designed game (Figure 1).

\section{Method}

\subsection{Maze and Mirror Game Concept}

Children at birth are natural scientists, engineers, and problem-solvers (Tony, 2011). They consider the world
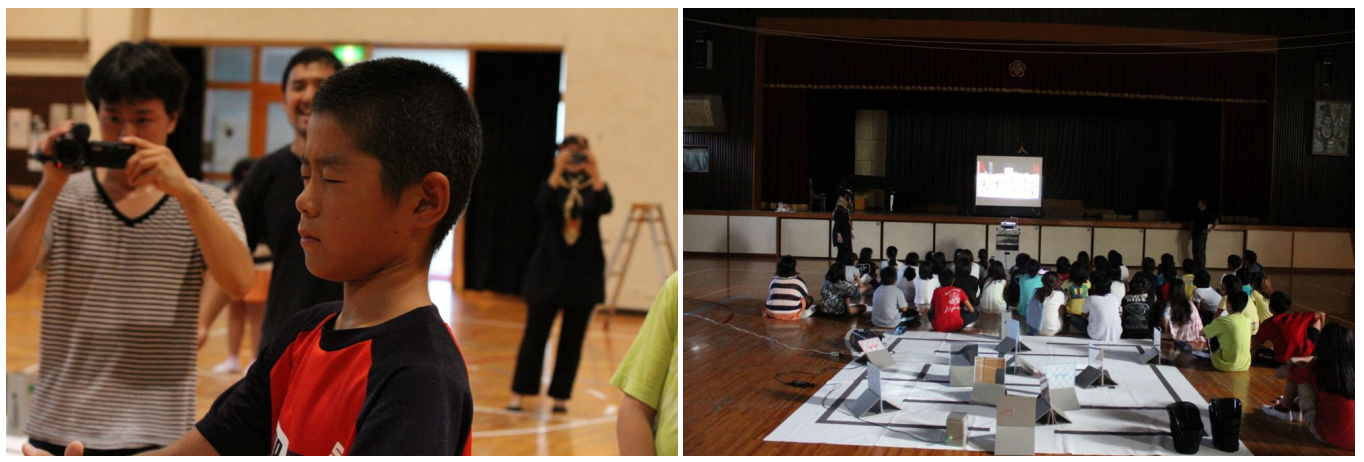

Figure 1. Real time video. 
around them and try to make sense of it the best way they know how: touching, tasting, building, dismantling, creating, discovering, and exploring. For kids, this isn't education. It’s fun. Children's play is not "supplemental" to their learning. It is their learning. So much of what children do, the activities they naturally engage in, are scientific inquiries. If their lead is followed, ways to use their play as a jumping off point to study a scientific subject more in-depth will be found (Renee, 2011). According to Einstein "Play is the highest form of research". He also said to his son "you learn the most, when you are doing something with such enjoyment that you don't notice that the time passes". Fred Rogers said "Play is often talked about as if it were a relief from serious learning, while for children, play is serious learning. Play is really the work of childhood”.

Toys and games are synonymous with play. Almost everyone likes to play and such a desire continues throughout an individual's life. Psychologists inform us that play is not just a filling in of an empty period, or just a relaxation or leisure activity, but it is an important learning experience (Norman, 1988). Science in the primary school can be real fun. Children everywhere are intrigued by science problems, either contrived or real ones from the world around them. If science teaching can focus on such problems, exploring ways to capture children's interest, no subject can be more appealing or exciting to young children [ibid]. Judy Ellis from the Toy Design Program at the Fashion Institute of Technology states that "a really great toy invites discovery, enhances a child's play environment, and is fun, educational, and age appropriate" (Levy \& Weingartner, 2003).

Mitchel Resnick in "All I really need to know (about creative thinking)" argues that the kindergarten approach to learning — characterized by a spiraling cycle of Imagine, Create, Play, Share, Reflect, and back to Imagine-is ideally suited to the needs of the 21st century, helping learners develop the creative-thinking skills that are critical to success and satisfaction in today's society. The materials and the creations vary, but the core process is the same" (Mitchel, 2007). He thinks of it as a spiraling process in which children imagine what they want to do, create a project based on their ideas, play with their creations, share their ideas and creations with others, and reflect on their experiences—all of which leads them to imagine new ideas and new projects [ibid] (Figure 2). Considering all these aspects, an indirect educational atmosphere based on a designed game can allow children to think, play and discover actively. Children will be motivated if they have the chance to do something by themselves and feel that they did it! In this research, two methods were considered for sharing. One involved sharing through consultation time in the game's group work, and the other sharing through reflection by RTV. The case of light, mirror and reflection were considered and a Maze and Mirror Game was designed to be used with the research subjects.

This Maze and Mirror Game combined with a science workshop creates a possibility for students to learn the concept of light and reflection in a fun atmosphere, communicate in groups, share and strengthen their ideas, and experience playful learning. There is the possibility of direct, hands-on learning and self-evaluation by seeing their interactions in their own groups and by seeing how other groups interact through reflection by RTV, integrating better learning with fun. It is expected that the learning procedure will increase their interest, activate their minds, and what they have learned will be retained longer (Figure 3).

\subsection{Maze and Mirror Game Design}

This game was initially developed for this research as an educational aid product in 2012 (Figure 4 and Figure 5). It is basically a conventional maze which is solved with light instead of a pen on paper. It is designed to teach stu-

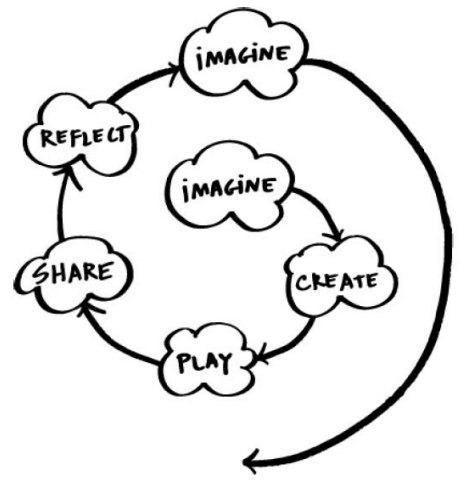

Figure 2. The kindergarten approach to learning (Mitchel, 2007). 


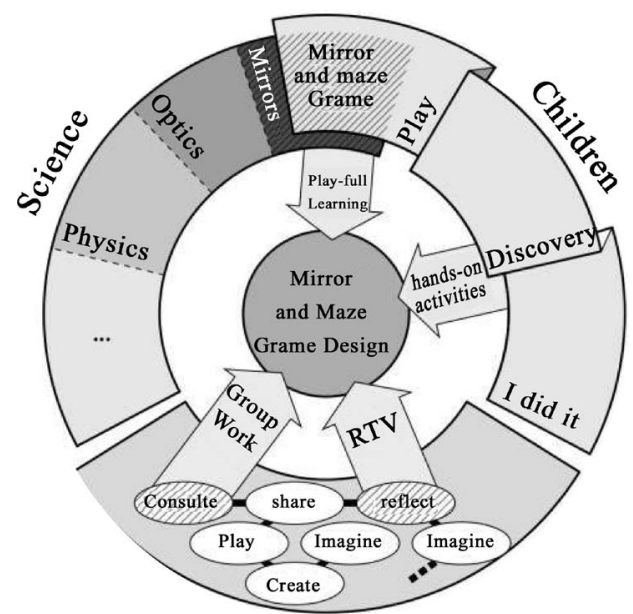

An approach to learning

Figure 3. Maze and Mirror Game concept.
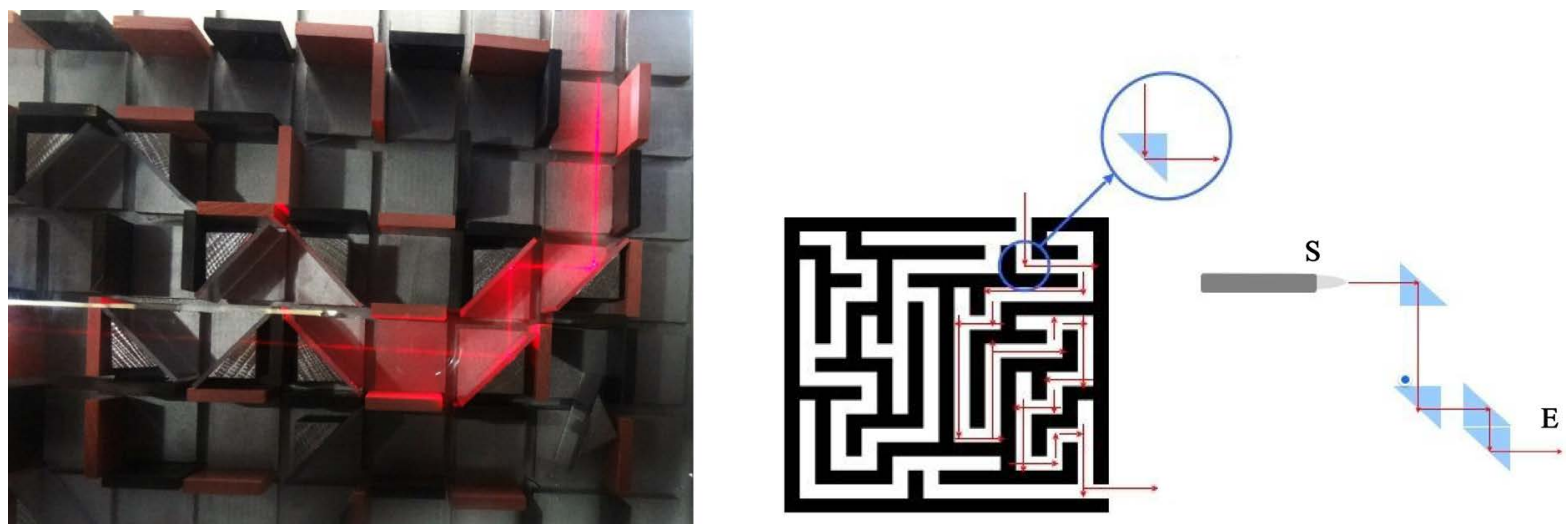

Figure 4. Maze and Mirror Game’s idea.
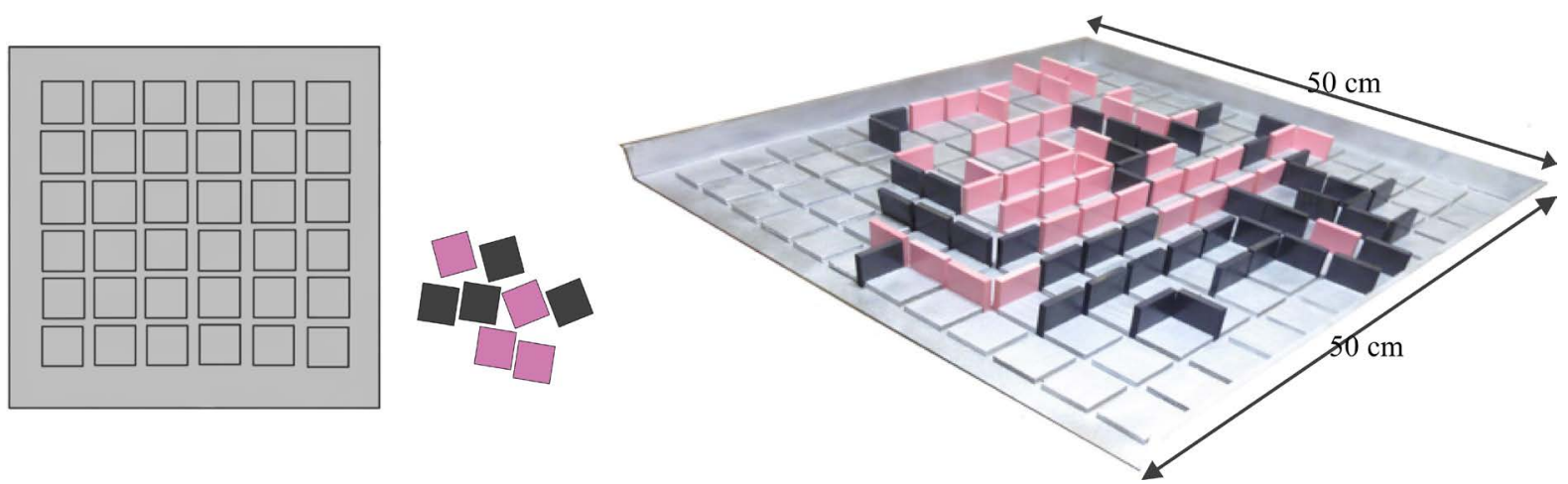

Figure 5. Maze and Mirror Game’s design.

dents about light and reflection while playing an enjoyable game.

A laser beam emits from the starting point and players direct it toward the correct path by using a mirror or prism, putting the reflective devices at the correct point with the proper orientation to divert the Laser beam to the right path and continue this manipulation until they reach the final goal.

This set is made of a wooden board covered with $3 \times 3$ centimeter flat cubes used to construct a passage. By fixing the flat cube pieces at different points along the passages, it is possible to make different maze patterns on the board. The board is colored silver and the pieces are dark grey and pink. There is also a laser as the light source, 
small mirrors with wooden stands and a fog producer (fogger or recurrence) that makes the laser beam visible.

\subsection{Maze and Mirror Game Re-Design for a Workshop}

A larger version of the game was redesigned to be used as a workshop. The game is played in a semi-dark room to make the laser beam visible, yet allowing for enough light to take videos for RTV.

This version consists of the following elements:

1) Fogger (American DJ) to make the laser beam visible (Figure 6(a)).

2) Maze pad, which is a $3 \times 3$ meter printed sheet of a maze pattern (Figure 6(b), Figure 6(c)). A maze pattern was downloaded from a maze generator website with ten turns. The pattern was redrawn in the illustrator at a resolution quality that enabled printing the design on a $3 \times 3$ meter plastic sheet. The maze pattern was divided into three parts and each $1 \times 3$ meter part was printed and connected from the backside (Figure 7).

3) High power laser pointers (to meet the need of multiple reflections).

4) Mirrors, A4 size (size considered necessary to make the reflection in ten mirrors in one game set reach its best usability.).

5) Innovative mirror bases made of plastic sheets designed to allow the mirrors to rotate around a horizontal axis ten centimeters from the ground, as well as rotate around the central vertical axis allowing the students to adjust the laser beam freely (Figure 8).

6) An optical buzzer assembled as a goal which beeps when a laser beam is detected and announces the successful end of the game. It is located on an A4 size sheet and its base is the same as the base used with the mirrors. A tetrahedron passage placed around the sensor on the board prevents other lights from triggering the sensor, thus preventing a continuous beep from the buzzer (Figure 9 and Figure 10).

\subsection{The Steps of Maze and Mirror Workshop}

Following the inspiration of Mitchel Resnick's spiraling process, the workshop steps were programed as seen in Figure 11 and Figure 12. In the preparatory step, the workshop and what students will do are explained to stu-

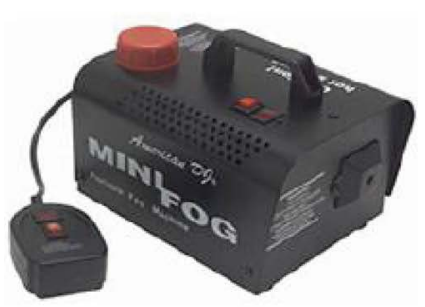

(a)

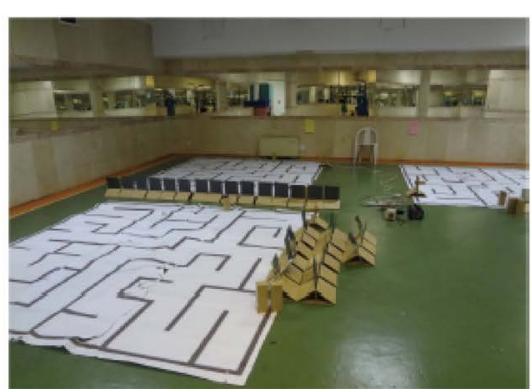

(b)

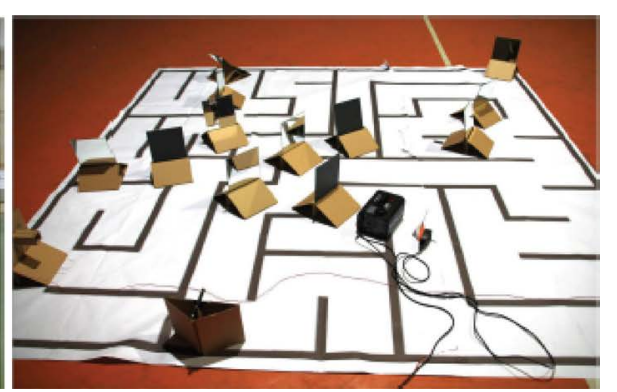

(c)

Figure 6. (a) Fogger; (b) Workshop set; (c) Game set.
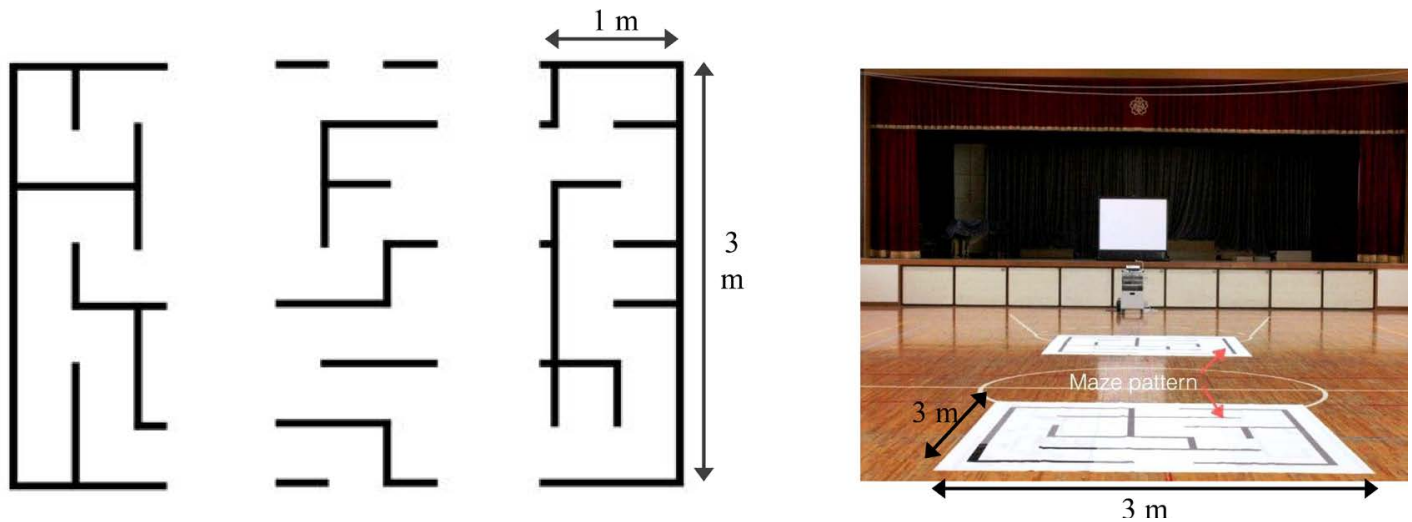

Figure 7. Maze pad. 

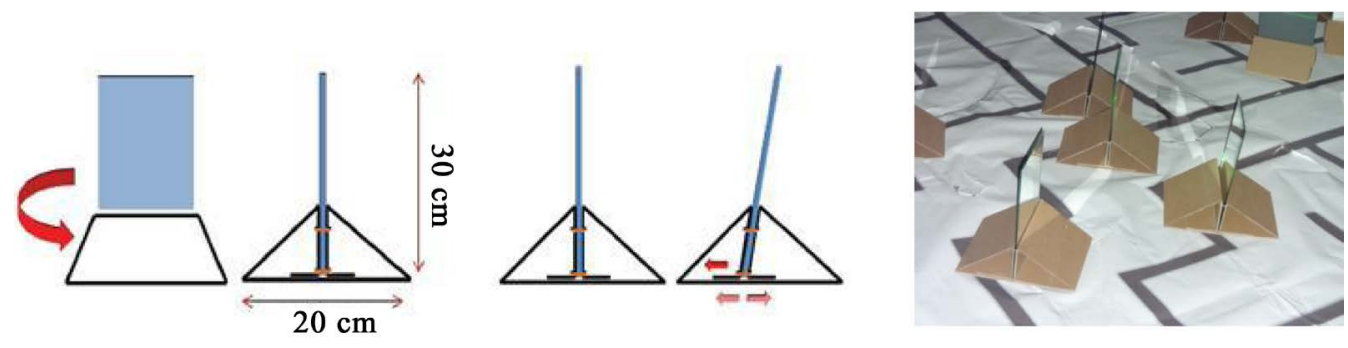

Figure 8. Mirrors and sensor's base, their rotations.

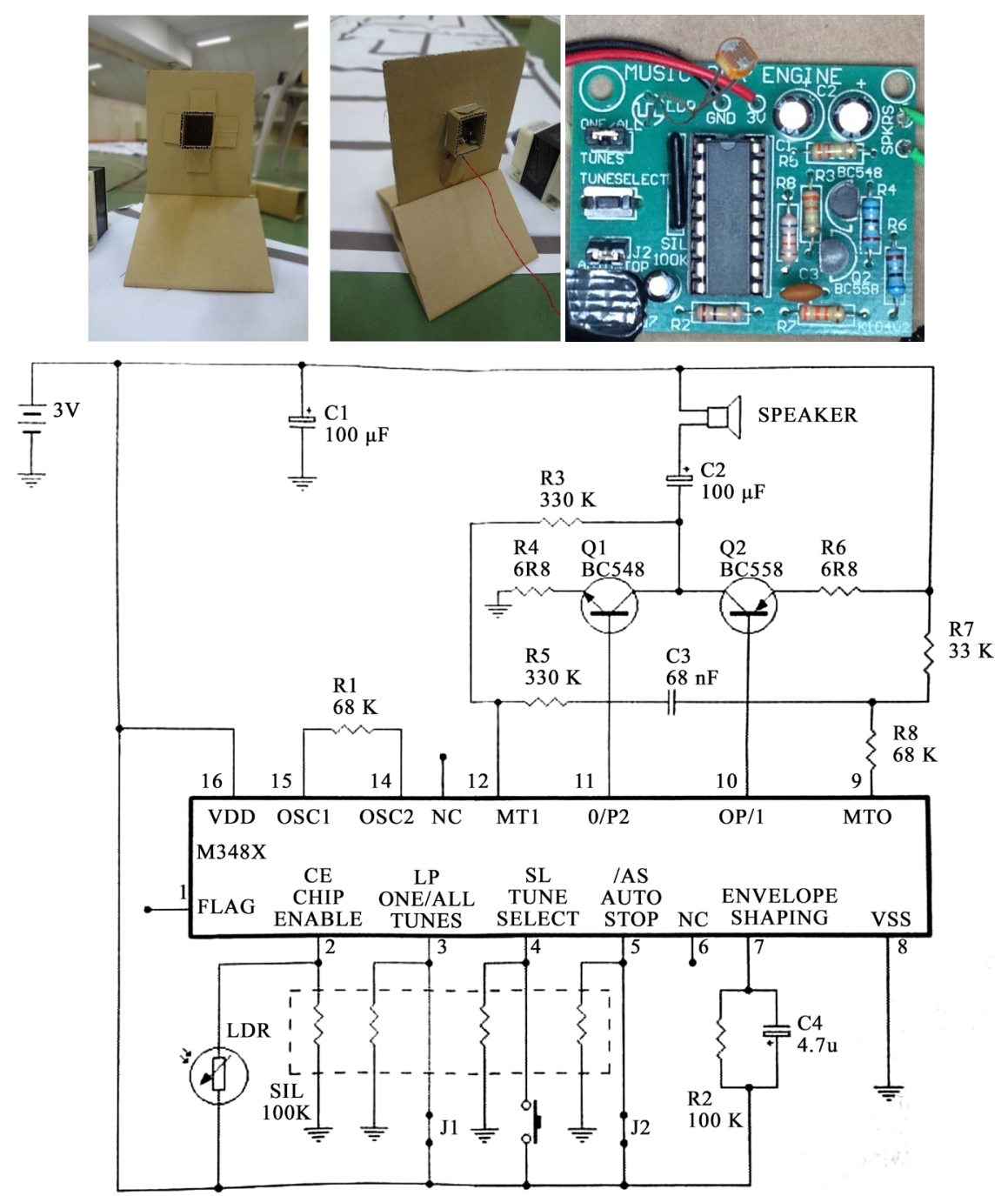

Figure 9. Light sensor (front side and backside), assembled kit and its circuit.

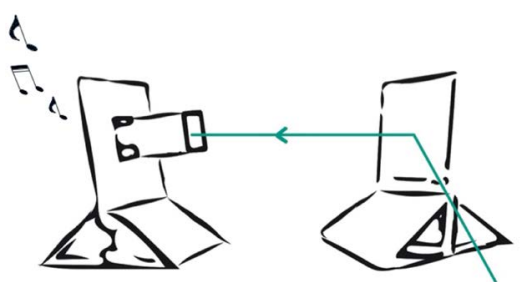

Figure 10. Mirror, sensor and the base and their function. 

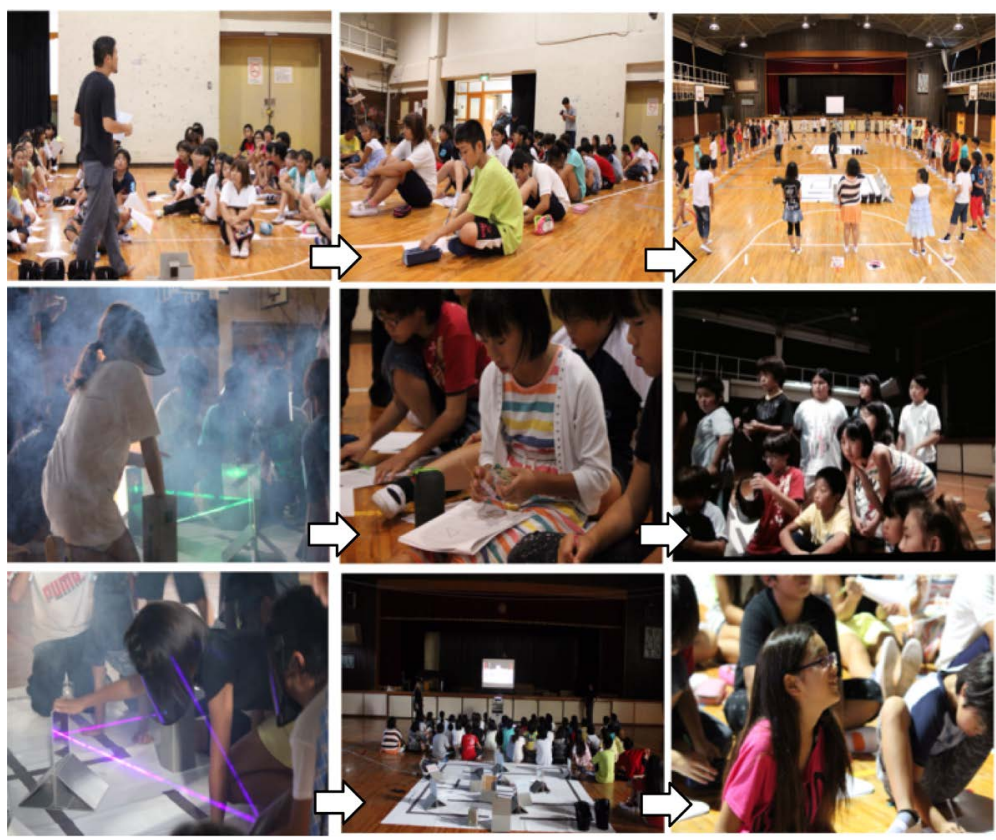

Figure 11. Workshop’s steps.

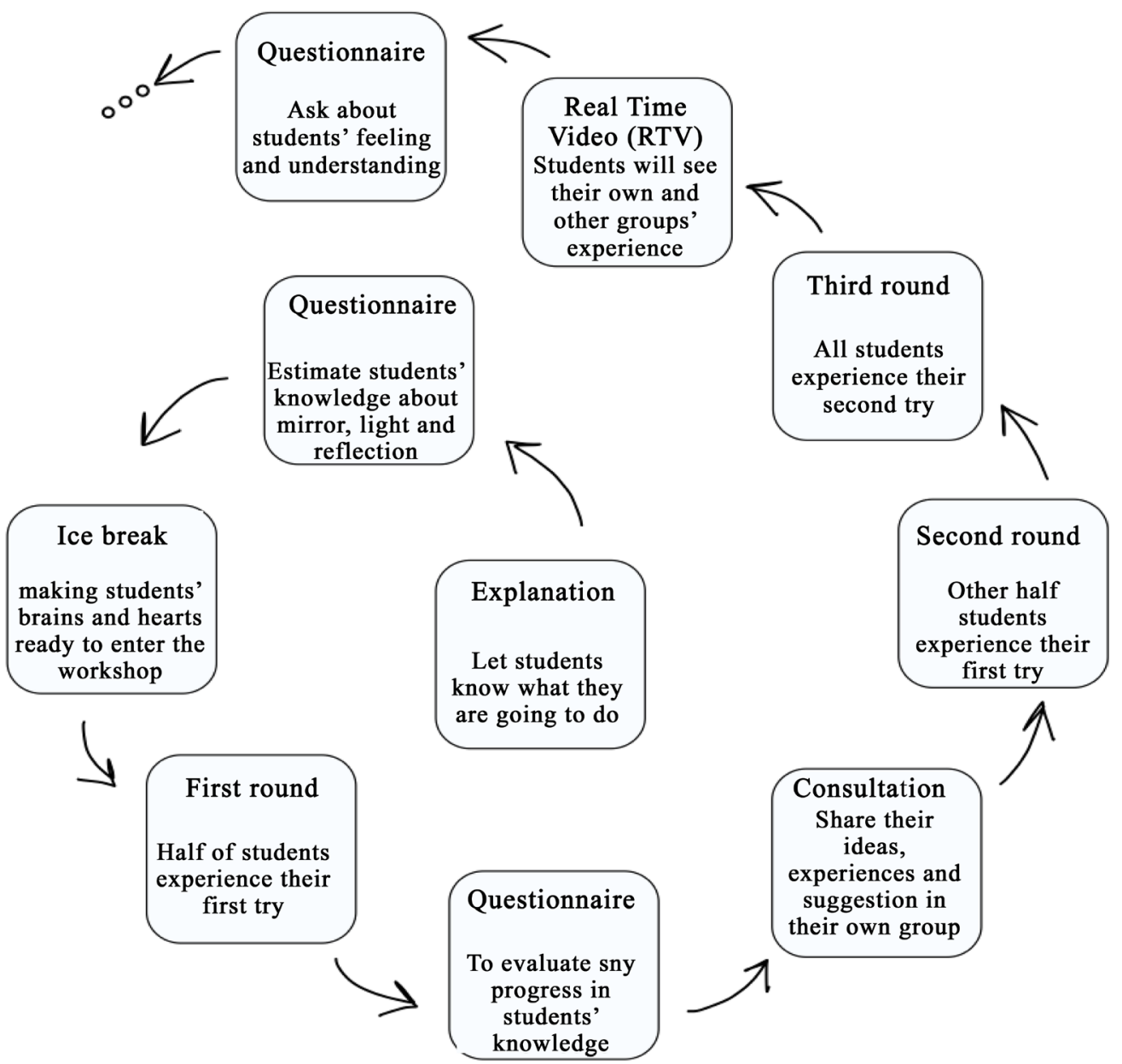

Figure 12. The spiral of workshop steps inspired from Mitchel Resnick’s approach. 
dents. Then a questionnaire about light and mirror is distributed among the students to collect information about their basic knowledge of the science that will be presented. After that, students gather in the workshop area for about 15 minutes for an ice-breaker that helps them to warm up mentally and become prepared for the main part of the workshop. The next step is the first round of the game in which the first two groups of students start to play the Maze and Mirror Game, competing with each other. The group which finishes first is the winner of the game. Each round of the game takes about 20 minutes. After the first round, the students fill in the same questionnaire to check their knowledge progress. Then a time is allocated to groups for consultation about what they have done, their experiences and ideas about how they should continue in order to win the game. This is followed by the second round of the game in which the other two groups of students participate and the first two groups are spectators. A third round follows in which all four groups enter the game and compete with each other to check on students' progress compared to their first rounds. After that, the RTV which reflects what students did during two hours of activity is shown for about five minutes. In the RTV students will see their own and other groups' experiences. The last step is answering a questionnaire about the workshop and the RTV which asks about students' feelings and understanding. In this workshop, there were two facilitators to help the students know what to do in each step, to motivate them, to help them to understand their feelings, and to ask them questions during question time as it is difficult for children to answer the questionnaires by themselves.

\subsection{Implementation of the Game in Shimada Elementary School}

This workshop was implemented in the Shimada Elementary School, (Osaka, Japan) on September 2013. A total of 44 students from two sixth grade classes attended. Six graders were considered because they matched to the game usability best as elementary school students. They were divided into four groups. Two groups, A1 and B1, competed in the first round, the other two groups, A2 and B2, competed in the second round, and all four groups competed in the third round. In each group, one person was responsible for fixing the laser pointer, one for the fogger and the others for placing the mirrors (10 mirrors had been prepared for each group). The workshop consisted of explanation, questioner time (1), break, first round, questioner time (2), consultation time, second round, third round, reflection by RTV and questioner time (3) (Table 1). Students' prior formal exposure to light and mirrors before the workshop was in third grade of elementary when they had a lesson named the nature of light (let's investigate the sunlight).

\section{Result}

\subsection{Students' Interactions with the Game and Contents}

The game set was successful and students could accomplish the game through three rounds of the game. Despite of uncomplicated theory of the game, practically transferring light through mirrors and fixing mirrors' angles was challenging for students and let them to be familiar with the concept of light and reflection as they revealed in their questioners. The performance of laser, maze sheet, mirrors, sensor and fogger was convenient. Music sound of the sensor that was played right after light reached to the end point was resulted in children's excite-

Table 1. Schedule of maze and mirror game workshop.

\begin{tabular}{cc}
\hline Steps & Time \\
\hline Explanation \& Questioner time (1) & $15 \mathrm{~min}$ \\
Ice break & $15 \mathrm{~min}$ \\
Game-first round & $20 \mathrm{~min}$ \\
Questioner time (2) & $10 \mathrm{~min}$ \\
Consultation & $5 \mathrm{~min}$ \\
Game-second round & $4 \mathrm{~min}$ \\
Game-third round & $7 \mathrm{~min}$ \\
Reflection by RTV & $5 \mathrm{~min}$ \\
Questioner time (3) & $10 \mathrm{~min}$ \\
& Total $91 \mathrm{~min}$
\end{tabular}


ment about the game's accomplishment. Just there was a need for a base for laser to be fixed on and move up and down freely. This will be helpful for more accuracy considering that light getting to the end point of the maze through several mirrors, and millimeter movement of laser can disrupt everything.

\subsubsection{Students' Sound Analysis Based on Their Excitement}

To study students' motivation considering their feeling through each round of the game, two upper cameras adjusted before the workshop. Through workshop's audio analysis yellow and red peaks were defined that yellow means peaks upper than $80 \% \mathrm{db}$ and red means upper than microphone capacity. The peaks were picked up in each round and compared with each other.

As it can be seen in the Figure 13, in the first round students were unfamiliar with the game although they received some explanation from the teachers. They were thoughtful about how they are supposed to encounter with the rules, concepts and their position in the game. But once they had started to play, they got along with it and in the last minutes of the game they got excited trying to accomplish the game. Considering the explanations this round was the longest one (twenty minutes) and yellow and red peaks show children's excitement in last minutes (Figure 13, part A). In the second round they had already understood how to play, how to transfer the light using mirrors and how to cooperate in each group. Yellow and red peaks in this round show students' excitement in the entire round and it took them just four minutes to finish the game (Figure 13, part B). The third round considering that students had entered the game all together, they neededpositioning again and it took them longer time and more thinking, although their excitement was more than first round that they had encountered with the game for the first time (Figure 13, part C and D and Figure 14).

\subsubsection{Studying about Students' Motivation and Learning Based on the Game}

An analysis of student answers to the questionnaires about light and reflection, as well as to the general questionnaires on students' motivating factors, yielded the following results.

Just $5 \%$ of the students responded positively when asked if they liked science before the workshop during the oral explanation time. In answer to the same question after the workshop, presented both orally and through the questionnaire, 50\% answered they liked science if "it is like this," meaning if it can be presented as it was in this workshop. The reasons students gave for what they like about science included "because it's interesting" (70\%), $30 \%$ said because it includes experiments. The answers reveal their preference for being involved in an experiment to learning science rather than receiving a lecture from a teacher.

Data from the questionnaires designed to evaluate student change in knowledge about light, mirrors and reflection revealed that $26 \%$ of them believed that they could learn something new in this game although they had some learning and lecture about light and reflection in their previous classes, and $74 \%$ of them answered that they could learn something new, even if it were just a little. All of their answers indicate that what they learned through this game is something that only can be learned in a practical activity. Their comments revealed a deeper understanding of concepts they have previously learned. The comments show how students paid attention in detail to different aspects of the game and learned even more than what the game was designed for. For example, the understanding that energy of a laser beam reduces as it goes through several mirrors was outside the expectations of the game. Generally students' answers show a good estimation of learning in the related subject (Figure 15).

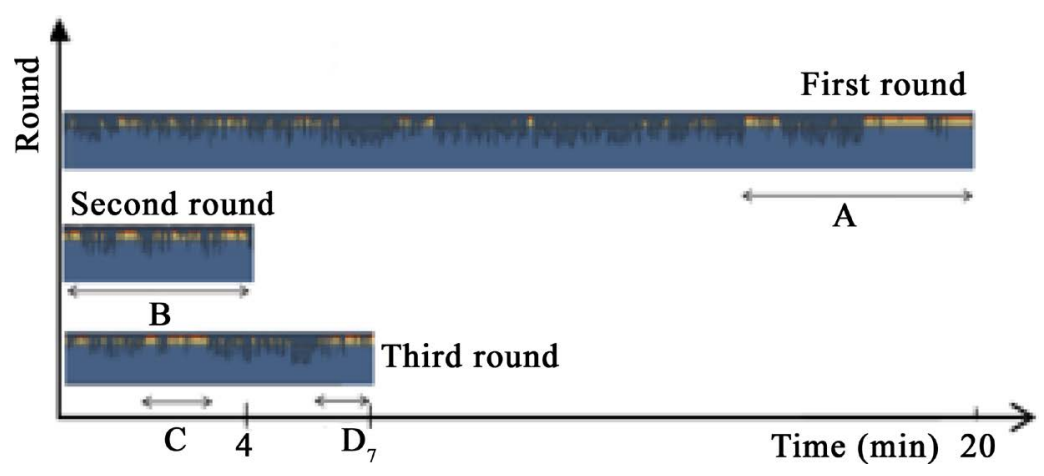

Figure 13. Students' excitement analyze based on their sound peaks. 


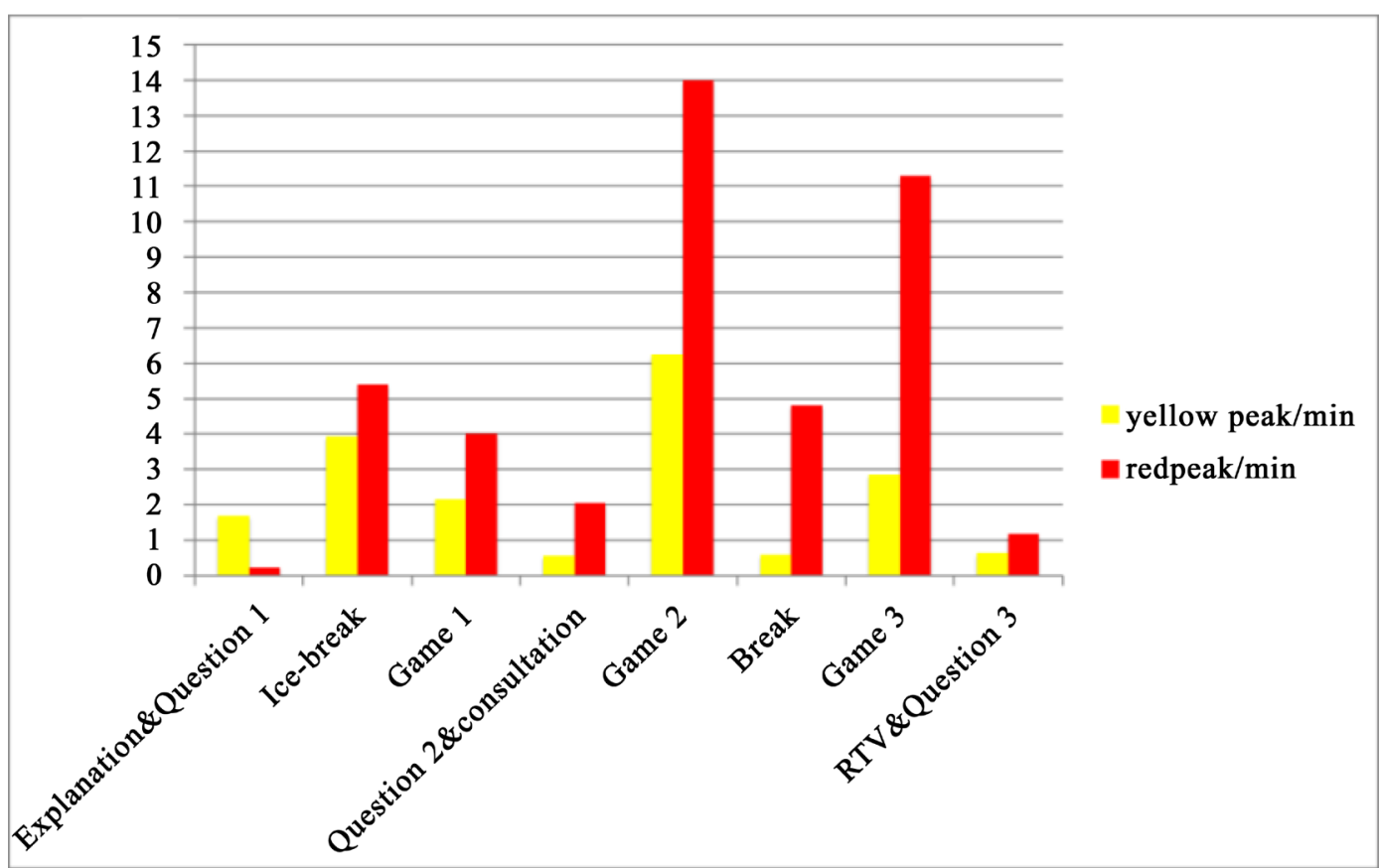

Figure 14. Students' sound analyzing in each part of the game workshop.

\begin{tabular}{|l|l|l|l|}
\hline $\begin{array}{l}\text { To go through a winding way, we } \\
\text { need mirrors. }\end{array}$ & $\begin{array}{l}\text { Entering and exiting } \\
\text { beam's angles should } \\
\text { be 90 to go through a } \\
90 \text { degree corner. }\end{array}$ & $\begin{array}{l}\text { Laser beam has the possibility to reflect } \\
\text { several times, although when it goes } \\
\text { through several mirrors, its energy } \\
\text { reduces. }\end{array}$ & $\begin{array}{l}\text { Entering beam's angle with } \\
\text { mirror and reflected beam's } \\
\text { angle are the same. }\end{array}$ \\
\hline $\begin{array}{l}\text { Flashlight's light diffuses at the } \\
\text { very beginning, while laser's light } \\
\text { diffuses far away. }\end{array}$ & $\begin{array}{l}\text { Mirror changes light } \\
\text { direction. }\end{array}$ & Light is visible where there is mass. & \\
\hline
\end{tabular}

Figure 15. Learning content about light, mirror and reflection revealed in the questioner.

When asked if they enjoyed the workshop, 91\% said very much, 9\% answered it was good. Students considering the differences between learning in science class and through a science game like that discussed here revealed what they valued about their experience was not just about learning, but also about interacting with others, and working outside the confines of a classroom. Their questioner responses show that the students enjoyed the game compared to their science classes because it included group-work, hands-on learning, playful learning (learning while playing), experiments, a different atmosphere, a wider space, the possibility of being active and the chance to experience a physics phenomenon (Figure 16).

Eighty-one percent of students expressed interest in having these kinds of workshops in their science classes, as one of them expressed that "It would be a good chance to have workshops like this once a month". Analyzing 
students' answers in the questioners generally revealed that what was motivating them in this research can be summarized in some main areas. One of them indicated as hands-on experiences. Students enjoyed moving their bodies while studying and being engaged in some tasks like changing mirrors' position. The other one can be presented as self-confidence. They enjoyed expressing their ideas and watching that they worked, they had the possibility to cope with their responsibilities in their groups, and they could find some new capabilities in themselves. Group-work is another case students enjoyed and benefited quite much of it. Thinking together, learning while cooperating and winning all together were some of their beliefs on benefits of group-work through this game. Also the feeling of accomplishment like as when they had been trying their best and with excitement were arranging the last mirror of the game was another achievement of this game in students' point of view. Having fun and atmosphere related items such as wide space and teacher's tension also helped them to increase their motivation. These finding demonstrate the success of the game in motivating students' interest in science (Figure 17).

Students were also asked to offer suggestions for improving the game and workshop, like using laser-preventing spectacles to stop laser beam going through their eyes instead of preventing-caps to breathe easier. Their comments were constructive for this game's future improvements.

The last part of the general questionnaire asked students to design some other games with the same materials. This was a difficult question for most of the students, but still some students' answers were remarkable. Engagement with the workshop served to activate the imagination of some of the students regarding reflection

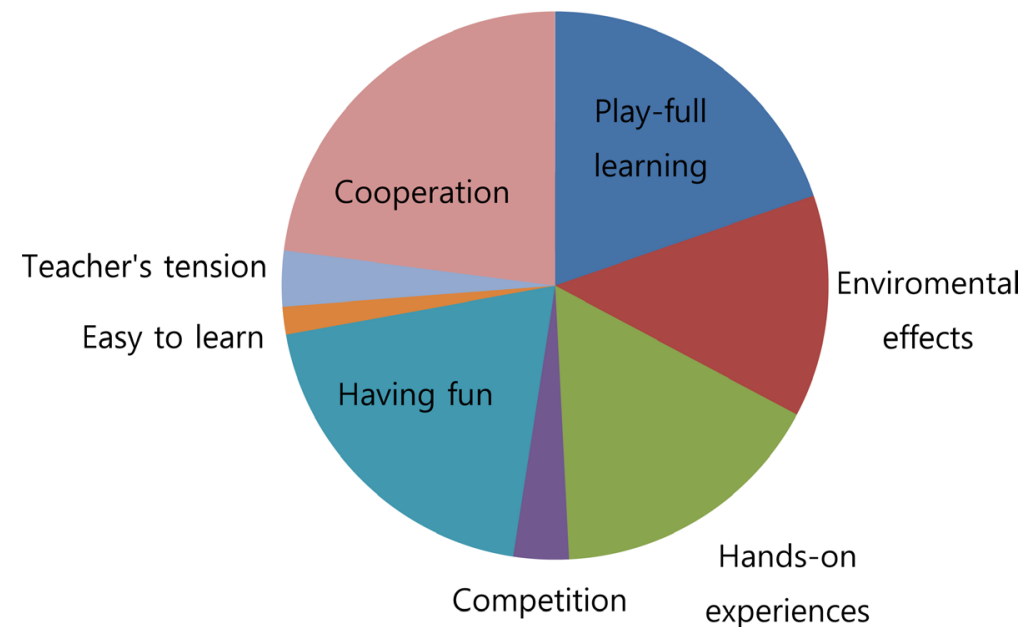

Figure 16. Game-based learning positive points through the questioner.

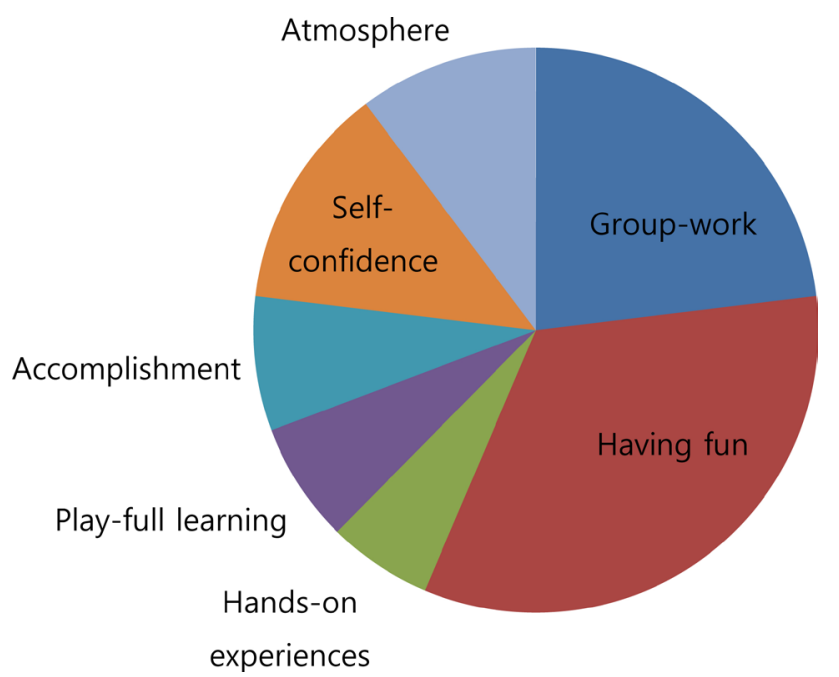

Figure 17. Motivating factors through students' answers in the questioner. 
principles as evidenced by their thinking about new games using the same materials. Such as 3D maze game, making a rainbow using different colors of laser and making shapes with a laser and mirrors. Some of these games would be possible to design quite interesting.

Regarding to the questions related to the RTV, students were asked how many times they saw themselves on the RTV, on average they noticed themselves nine times in a four minute video, which reveals that RTV worked effectively for them and they paid attention to it.

When asked to describe their facial expressions through the RTV, 26\% answered happy, 26\% answered serious, and others answered with other replies like normal and I couldn't understand. Their feelings about themselves were mostly a combination of happy and serious reveals that they were working seriously on the game in a fun atmosphere.

The range of responses when they were asked about their favorite part of the workshop, not only reveal the students' enthusiasm for the activity, but also shows that aspects of the work was enjoyable, like cooperating with each other, or doing their best to complete the project.

When asked which part of the workshop they considered as a point of success their responses confirmed their favorite aspects of the game, indicating that students felt motivated to succeed, found the work enjoyable and learning-full, and could see what was considered as their ideas helped the group to accomplish the game.

Students were given ten descriptive statements to circle to evaluate their overall impression about using the RTV combining to the game. The answers confirm that the participants learned about their thoughts and feelings through watching the RTV. It helped them to watch themselves. They could see what they had done, how they looked and how they felt. Although they knew what they had done, when watching themselves in the video allowed the students to experience the difference between understanding something in their minds and watching it in front of them as one of them expressed "While I was watching the video, I could see everything clearly and it was wonderful”. This may be more effective for children for whom it is difficult to express their feelings and speak about their thoughts to analyze their learnings and feelings and let those analyzes reflect on their next learning steps. They could see which part they did well and where they could try harder. Also they could study interactions in both their own groups and the other groups while the positive points in themselves and their own groups will increase their self-confidence and positive points in other groups will help them to learn new aspects of learning, feeling and interacting, which may help them in their future interactions (Figure 18).

\section{Discussion}

The game designed in this research provided the opportunity for the children to learn different aspects of light,

I want to make an RTV video myself

The camera above us caught my attention

I paid attention to my friends

I behaved differently than usual

I discovered something new about myself

$$
\text { I felt shy }
$$

It was not interesting

Nothing special

Somewhat interesting

It was interesting

$0 \%$

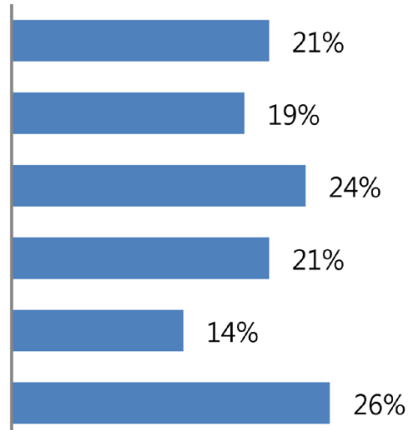

$0 \%$

$2 \%$

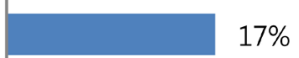


mirror and reflection through a play-full workshop. Students' answers to the questioners regarding to increasing their motivation and learning chances had an emphasis on four main areas, integrating self-confidence with feeling of accomplishment in this research, and having fun with play-full learning on the other hand. First, they could experience playful learning. They enjoyed playing with fog, moving the mirrors, using lasers and watching how they work. Play-full learning atmosphere prepare a situation for children to learn in free space, activate their minds, engage more and enjoy more as play is work of childhood. Second, they benefited from their groupwork. Almost all the students enjoyed cooperating while doing their best to complete the maze. They felt their victories were special because they belonged to the group. Children in the structured groups were more willing to work with others on the assigned tasks and they provided more elaborate help and assistance to each other. Furthermore, as the children in the structured groups had more opportunities to work together, they developed a stronger perception of group cohesion and social responsibility for each other's learning (Gillies, 2004). Group-work helps students feel unity, consulting in their tasks, and each child has the possibility to be assigned to do what matches to his personality. All of these are effective for children to be motivated in learning, considering their minds and feelings getting prepared for a better condition and learning process will be easier and more interesting for them. Third, by this game they had a chance to learn through a hands-on experience. They enjoyed being able to set up the laser, the fog machine and the mirrors, and moving the mirrors and seeing how that caused a change in the laser beam's direction. A research has been conducted to compare student achievement in activity settings versus text lecture settings indicated that students in a classroom where hands-on activities were used as instructional strategies displayed evidence of understanding the material of the lesson. Students in the text/lecture class were "less engaged, misbehaved, inattentive, and more passive" (Zady, 2003). Hands-on activities well serve students in the case of student-based learning, providing them free discoveries combined with desire. The final category is a feeling of success and accomplishment. They tried their best in the game and they enjoyed talking about their suggestions that caused them to win. In this game, as students should accomplish the game from the beginning to the end, they felt that they could do something that was produced of their own thoughts and tries, while indirectly there was the chance for them to learn about the field subject.

What caused them to like the game was revealed through comments such as they had the chance to learn about light and reflection concepts in a different enjoyable condition such as reflection angle and energy decreasing of light when it's reflecting several times, the possibility to experience something by themselves, they could express their opinions and see how their ideas worked in the game, they had the chance to work with each other as a group, they played with the elements of the game and learned through playing with them, they enjoyed the maze game and competing with each other (Figure 19).

\section{Conclusion}

The Maze and Mirror Game was initially designed for this research in 2012 with the purpose of motivating elementary school students in science, specifically physics. This game was redesigned in 2013 on a bigger scale to be held as a workshop for students to study its effect on student motivation for science learning. The game in the Shimada elementary school in Japan was studied and the results revealed that students could develop their knowledge of light and reflection and they were impressed by the game as a new atmosphere in which to learn while they are playing. They learned more than what was expected from this game in terms of both theoretical physics and its practical application. For example, students learn that a laser beam enters and exits a mirror at the same angle. They also learn that when a laser beam is reflected by several mirrors, the beam becomes thinner. This is something that can only be learned through practical or hands-on experience. They enjoyed working with their hands with new things in a new learning atmosphere as much as they enjoyed working together, doing something by themselves and watching themselves through the RTV. They had useful suggestions to create a better game and believed that advantages of the workshop over their normal science classes are the possibilities of learning while having fun, learning in person rather than studying books or taking notes, studying and interacting in a bigger space than their classroom, cooperating with classmates, discussing their opinions and, being involved in the learning process, which one of them expressed by saying "I felt the game with my body". Some of them had practical suggestions to make new games with the same materials. They also had the chance to evaluate themselves in a Real Time Video (RTV). Their answers to the RTV questionnaire showed their attention in all aspects, their learning and feelings, their facial expressions and the extent to which they were successful encountering with the game and how they believed they could improve. A better stand for laser pointer that may 


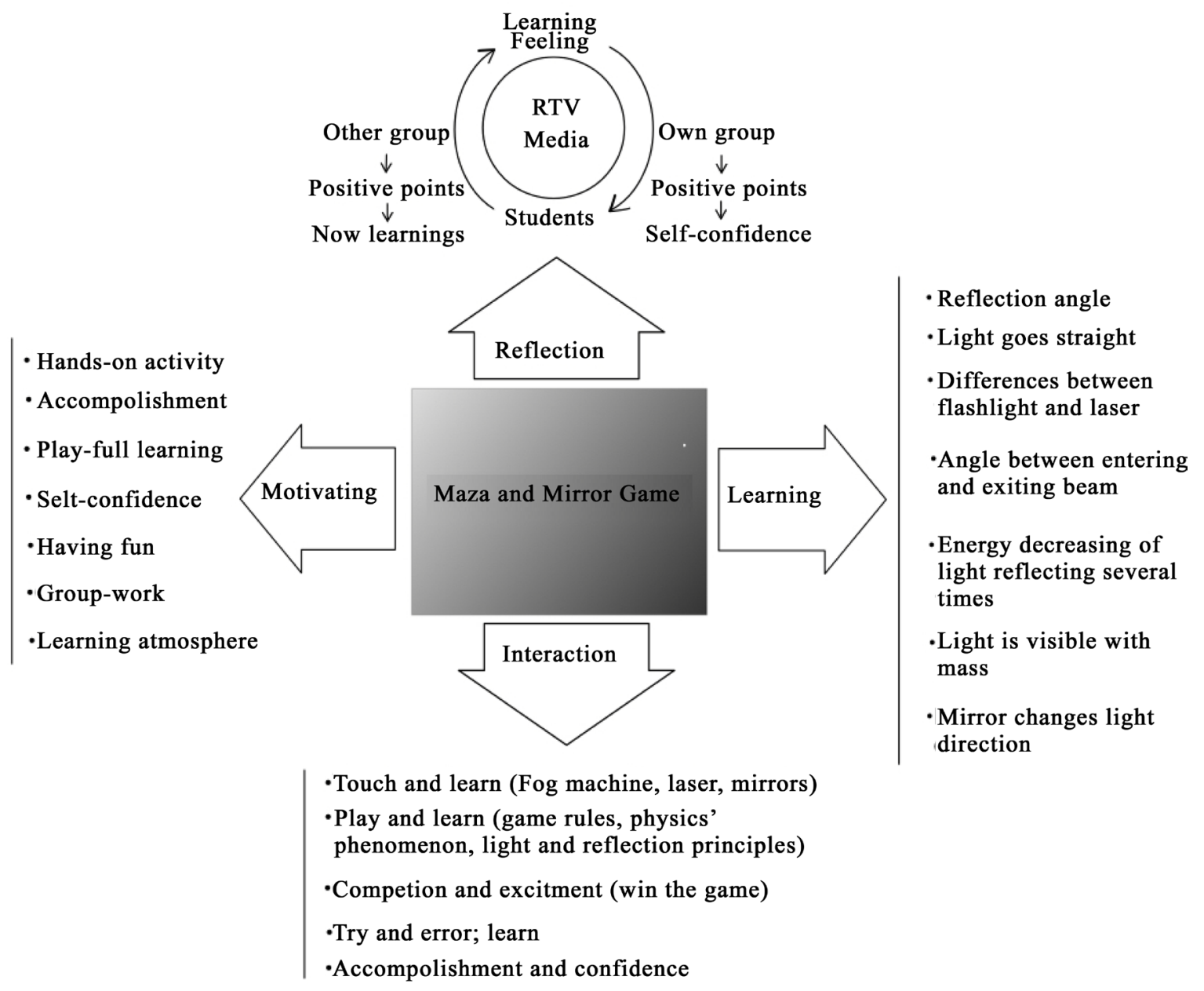

Figure 19. Maze and Mirror game and concluding factors considering students’ interaction with the game.

have the possibility to move in any direction smoothly would be helpful for students to transfer light with more accuracy. For future research steps, it could be a great chance to study this group over other students in other classes which just received normal science lectures.

\section{References}

Bartley, J. E., Mayhew, L. M., \& Finkelstein, N. D. (2009). Promoting Children's Understanding and Interest in Science through Informal Science Education. AIP Conference Proceedings, 1179, 93-96. http://dx.doi.org/10.1063/1.3266763

Finkelstein, N., Adams, W., Keller, C., Perkins, K., Wieman, C., The Physics Education Technology Project Team. (2006). High-Tech Tools for Teaching Physics: The Physics Education Technology Project. Journal of Online Teaching and Learning.

Laws, P., College, D., Sokoloff, D., \& Thornton, R. (1999). Promoting Active Learning Using the Results of Physics Education Research. UniServe Science News, 13.

Levy, R. C., \& Weingartner, R. O. (2003). The Toy and Game Inventor's Handbook, Alpha.

Mitchel, R. (2007). All I Really Need to Know (about Creative Thinking) I Learned (by Studying How Children Learn) in Kindergarten. C\&C 07 Proceedings of the 6th ACM SIGCHI Conference on Creativity \& Cognition, 1-6.

Norman, K. L. (1988). Division of Science Technical and Environmental Education UNESCO. Games and Toys in the Teaching of Science and Technology.

Redish, E. F. (1994). Implications of Cognitive Studies for Teaching Physics. American Journal of Physics, 62, $796-803$. http://dx.doi.org/10.1119/1.17461

Renee (2011). 4 Simple Methods for Teaching Elementary Science. 
Spencer, T. L., \& Walker, T. M. (2015). Creating a Love for Science for Elementary Students through Inquiry-Based Learning. Journal of Virginia Science Education, 4, 18-25.

Tony, M. (2011). STEM Education-It's Elementary, Elementary School Teachers Need to Be Educated in Science and Math.

Zady, M. F., Portes, P. R., \& Ochs, V. D. (2003). Examining Classroom Interactions Related to Difference in Students' Science Achievement. Science-Education, 87, 40-63. http://dx.doi.org/10.1002/sce.1053 